\title{
Survey of medical genetic services in Italy: year 2011
}

\author{
Daniela Giardino ${ }^{1 *}$, Rita Mingarelli ${ }^{2}$, Tiziana Lauretti ${ }^{2}$, Antonio Amoroso $^{3}$, Lidia Larizza ${ }^{1,4}$ and Bruno Dallapiccola ${ }^{2}$
}

\begin{abstract}
Background: The aim of this study was to collect information about 2011 genetic activities in Italy, with the purpose of providing guidance to the national health systems in order to improve genetic services.

Methods: A web-based survey was carried out to achieve the information.

Results: Data were collected from 268 macrostructures hosting 517 services and employing 3246 persons. About 295,000 cytogenetic, 35,000 immunogenetic and 263,000 molecular genetic analyses of 902 genes were recorded. Seventy-four percent of the services were accredited with institutional bodies and $57 \%$ were also certified according to ISO 9001 standard. Twenty percent of cytogenetic laboratories had participated in an European External Quality Assessment (EQA) while $44 \%$ participated in a national EQA. Only $28 \%$ of the molecular laboratories had participated in a national Cystic Fibrosis EQA. The percentage of diagnoses confirmed by genetic tests varied among disorders, ranging from $52 \%$ for coeliac disease to $4 \%$ for fragile $X$ syndrome.

Conclusions: This study highlights the need for reorganizing the Italian genetic services network, improving EQA participation and developing national plans for implementing next generation technologies. Concerted effort has to be addressed in the education of the professionals prescribing tests to improve appropriateness and to inform patients, who now have exposure to direct-to-consumer multifactorial genetic testing where clinical utility is unproven.
\end{abstract}

\section{Background}

The Italian Society of Human Genetics (SIGU) launched in 2012 a survey designed to scrutinize the 2011 activities of the Italian Medical Genetic Services, to compare the results with previous data collections, and to update the national scenario. SIGU had previously carried out six surveys to gather information on cytogenetic and molecular testing and clinical genetics activities, with the aim of providing guidance to the national and regional health systems to improve the organization of genetic services $[1,2]$.

Here, we report the results of this last study, providing an overview of the changes occurred over a 4-year period, highlighting the need for reviewing and improving the Italian genetic structure network, in line with the current public health requirements.

\section{Methods}

The survey refers to the medical genetic activities performed in Italy from January 1st to December 31st, 2011.

\footnotetext{
* Correspondence: giardino@auxologico.it

${ }^{1}$ Laboratorio di Citogenetica, IRCCS Istituto Auxologico Italiano, Milano, Italy Full list of author information is available at the end of the article
}

This study was carried out by the Bambino Gesù Children Hospital in Rome, in collaboration with OrphanetItaly, on behalf of SIGU. Ethical approval for this study was granted by SIGU. Data were gathered by an ad hoc questionnaire (http://docs.biomedia.net/SIGU/SchemaCensimento_SIGU-2011.pdf) sent to genetic centers hosted by universities, research hospitals (Istituti di Ricovero e Cura a Carattere Scientifico - IRCCS), general hospitals, local health centers (Aziende Sanitarie Locali ASLs) and commercial laboratories. The enrolled genetic centers were those registered and updated from the 2007 survey, integrated with others recruited through Orphanet database (www.orpha.net) or joining voluntarily to this initiative after learning of it during national scientific conferences or through the SIGU website (www.sigu.net). A verbal informed consent was obtained from participants.

Questions from previous surveys were reiterated and new ones added, in order to achieve information on the activities of immunogenetic laboratories and diagnostic tests becoming available in more recent years (i.e. microarrays). Entered data were based on selfcertification. Information was collected online from March 
to July 2012, using forms available in a dedicated website. Each participating center accessed the website through a private username and password assigned during the registration process. Requested data included total number and type of performed cytogenetic and molecular genetic tests, clinical genetic activities such as the number and type of genetic counseling sessions. Data concerning the personnel attending laboratories and clinical activities were also collected. The quality management system of the responding centers in terms of national accreditation standards and international certifications was investigated, together with national and international External Quality Assessment enrolment. By comparing the number of analyses with the number of diagnoses confirmed by the test results, appropriateness was evaluated for the following entities: achondroplasia, Angelman, DiGeorge, fragile X-mental retardation, Noonan, Prader-Willi and Williams syndromes, ankylosing spondylitis and coeliac diseases. Appropriateness was investigated also for CGH (Comparative Genomic Hybridization) and SNPs (Single Nucleotide Polymorphisms) array tests.

\section{Results}

\section{Genetic Centers}

Overall, 268 genetic centers, hosting 517 genetic services (genetic testing and counselling) were surveyed (Table 1). $25 \%$ of these services were located in public hospitals, $21 \%$ in university hospitals, $21 \%$ in IRCCS, $16 \%$ in private centers, $9 \%$ in ASLs, $5 \%$ in universities, and $4 \%$ in a different institution (Fig. 1). The genetic units included 145 clinical services and 372 diagnostic laboratories, comprising 153 cytogenetic, 198 molecular, and $21 \mathrm{immu-}$ nogenetic laboratories (Table 1). By comparing the number of the 2011 censused structures with the previous two surveys, an increase of clinical genetic services appeared evident with a slight decrease in the cytogenetic and molecular genetic laboratories (Fig. 2). The collected data was representative of the genetic services in Italy as a whole. A decreasing gradient of the total number of genetic centers from North to South and to the Islands of Italy was observed in previous studies and was substantiated in the present analysis (Table 1). A total of 3246 persons were employed in the national genetic services, of which $38 \%$ biologists, $21 \%$ technicians, $16 \%$ medical doctors, $6 \%$ biotechnologists, $1 \%$ bioinformaticians, $1 \%$ graduated in different disciplines, $7 \%$ healthcare personnel, $9 \%$ administrative, and $2 \%$ other staff (Fig. 3). Centers that had adopted a Quality Management System are shown in Table 2: $74 \%$ of the services were institutionally accredited by regional bodies. In addition to this institutional accreditation, $57 \%$ of services were also voluntarily certified according to ISO (International Organization for Standardization) 9001 standard, $7 \%$ accredited according to ISO 15189 , about $5 \%$ to SIGU and $4 \%$ to JCI (Joint Commission International) standards. Seven out of 21 immunogenetic laboratories had obtained the EFI (European Federation for Immunogenetics) accreditation.

\section{Cytogenetic laboratories and activity}

Forty-six percent of cytogenetic laboratories were located in the Northern regions, compared with $21 \%$ in Central regions, $20 \%$ in Southern regions, and $11 \%$ in the Islands (Table 1). The total number of cytogenetic laboratories had decreased slightly compared to 2007 (Fig. 2), and the total number of analyses dropped from 312,881 in 2007 to 294,155 in 2011 (Table 3). This diminution occurred in both the constitutional prenatal and postnatal tests, and this decrease may be a consequence of their replacement by the molecular tests. For example, in 2011 a total of 19,908 QF-PCR (Quantitative Fluorescent- Polymerase Chain Reaction) were performed (the 2007 figure is not available) negating the need for full chromosome analysis in some cases. In addition, 1862 prenatal microarray tests were undertaken (compared to 393 in 2007).

Cancer cytogenetic tests increased from 2000 onwards with the greater contribution for this escalation being attributable to an increase of FISH (Fluorescent In Situ Hybridization) and ISH (In Situ Hybridization) analyses.

One aspect of a Quality Management System is the participation in an accredited external quality assessment (EQA) scheme. Only 30 of 153 censused laboratories $(20 \%)$ had taken part in an international accredited Cytogenetic European Quality Assessment (CEQA, now

Table 1 Geographical distribution of the censused structures

\begin{tabular}{lccccccccccc}
\hline Area & Medical & $\%$ & \multicolumn{9}{c}{ Genetic services } \\
\cline { 2 - 11 } & genetic centers & & $\mathrm{CL}$ & $\%$ & MGL & $\%$ & IGL & $\%$ & CGS & $\%$ & Total \\
\hline Northern & 142 & 53 & 70 & 46 & 101 & 51 & 8 & 38 & 68 & 47 & 247 \\
Central & 54 & 20 & 32 & 21 & 45 & 23 & 7 & 33 & 34 & 23 & 118 \\
Southern & 45 & 17 & 31 & 20 & 34 & 17 & 5 & 24 & 30 & 21 & 100 \\
Islander & 27 & 10 & 20 & 13 & 18 & 9 & 1 & 5 & 13 & 9 & 52 \\
Total & 268 & & 153 & & 198 & & 21 & & 145 & 517 \\
\hline
\end{tabular}

CL Cytogenetic Laboratories, MGL Molecular Genetic Laboratories, IGL Immunogenetic Laboratories, CGS Clinical Genetic Services, \%, \% of structures located in a specific geographic area out of the total of the censused structures 


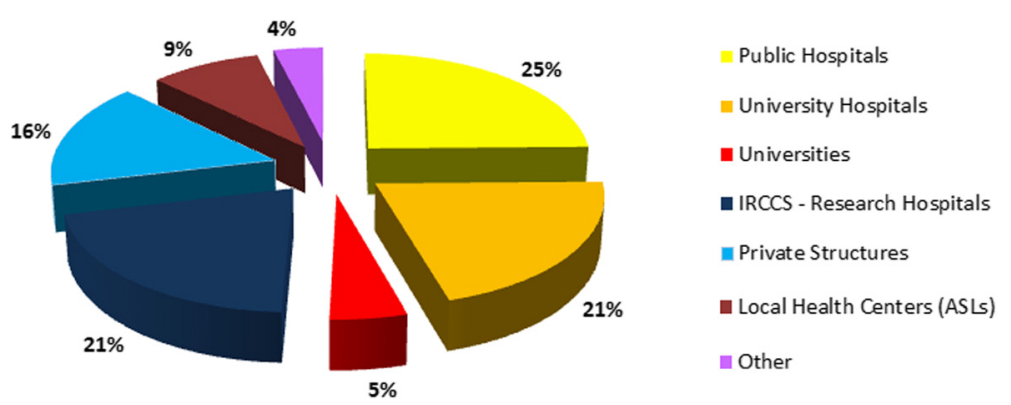

Fig. 1 Distribution by affiliation of the 517 services performing genetic activities during 2011 in Italy

known as CEQAS) (Fig. 4) and 68 (44\%) in the national cytogenetic EQA scheme (personal communication provided by Italian National Centre for rare Diseases Istituto Superiore di Sanità, Rome, Italy). Figure 4 also shows that the number of laboratories that effectively participated (enrolled) in an international QA (Quality Assessment) is lower than that registered to attend.

\section{Molecular genetic laboratories and activity}

Fifty-one percent of 198 molecular genetic laboratories were located in Northern regions, $23 \%$ in Central regions, $17 \%$ in Southern regions, and $9 \%$ in the Islands (Table 1). The number of surveyed molecular analyses $(263,246)$ increased by $6 \%$, compared to the 2007 study $(248,691)$ (Fig. 5). The total number of analyzed genes was 902 (Table 4), a figure consistently higher compared with previous 2007 report (556), which is starting to bridge the previous gap between the number of analyzed genes and the number of disease genes amenable for investigation [3]. Seventy percent of the molecular tests
(184,679 of 263,246 analyses) included 15 disease genes or group of genes, the analysis of CFTR gene accounting for $21 \%$ of total (Table 5). Tests of susceptibility to common diseases comprised about 64,000 tests $(24 \%$ of the total), mainly exploring genes within the thrombophilia cascade and about 18,000 analyses (6\%) of the major histocompatibility complex (HLA), primarily for disease association studies (Table 5). In the 2007 survey, the susceptibility tests accounted for about $37 \%$ of all molecular analyses.

Only 55 of 198 molecular genetic laboratories (28\%) participated in either a national or international cystic fibrosis EQA schemes. It is likely that not all the 198 censused laboratories offered genetic testing for cystic fibrosis, but the majority did, although the participation in EQA was lower than desirable.

A total of 35,446 molecular genetic analyses had been performed by 21 immunogenetic laboratories in 2011, indicating a sharp and constant increase during the last 12 years (Fig. 6).

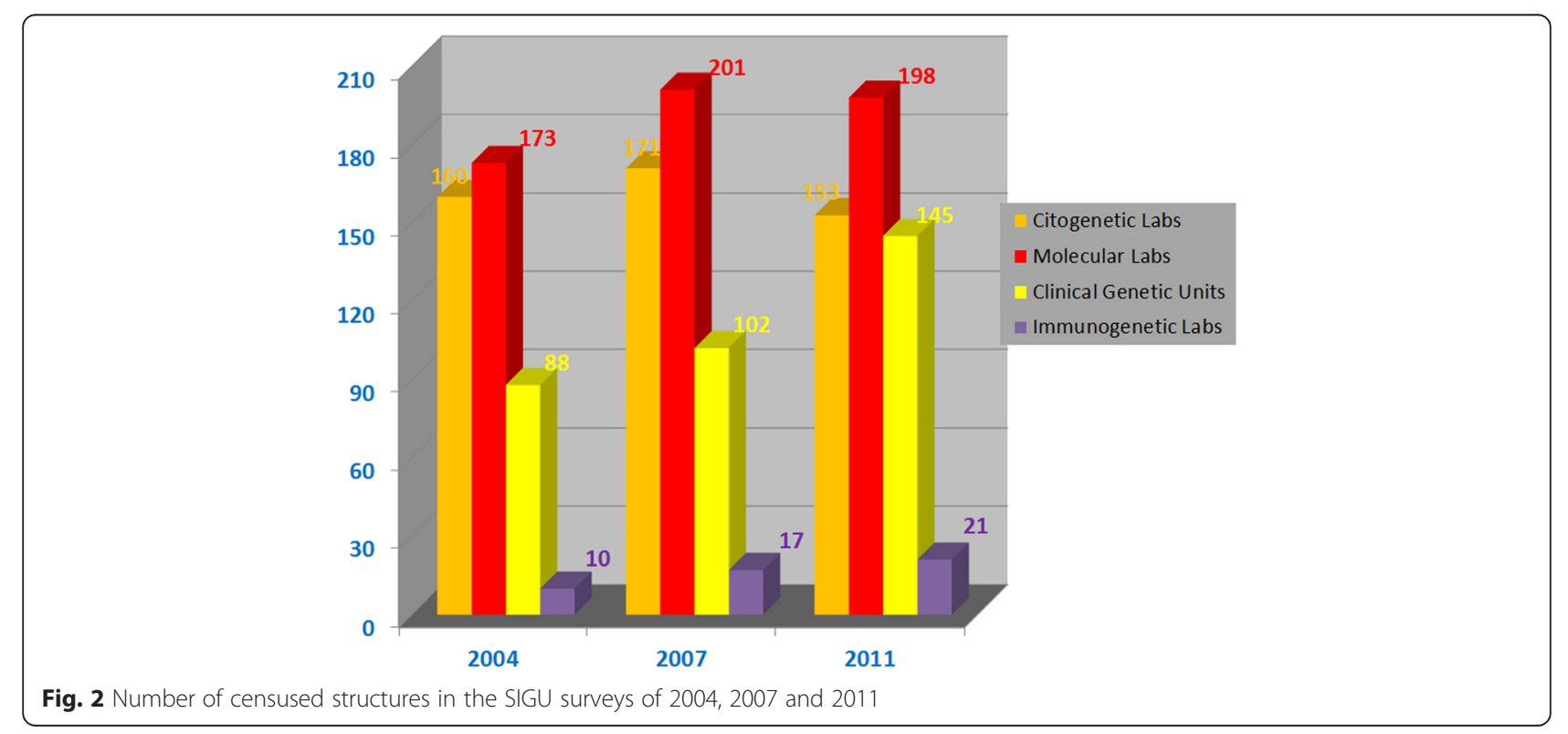




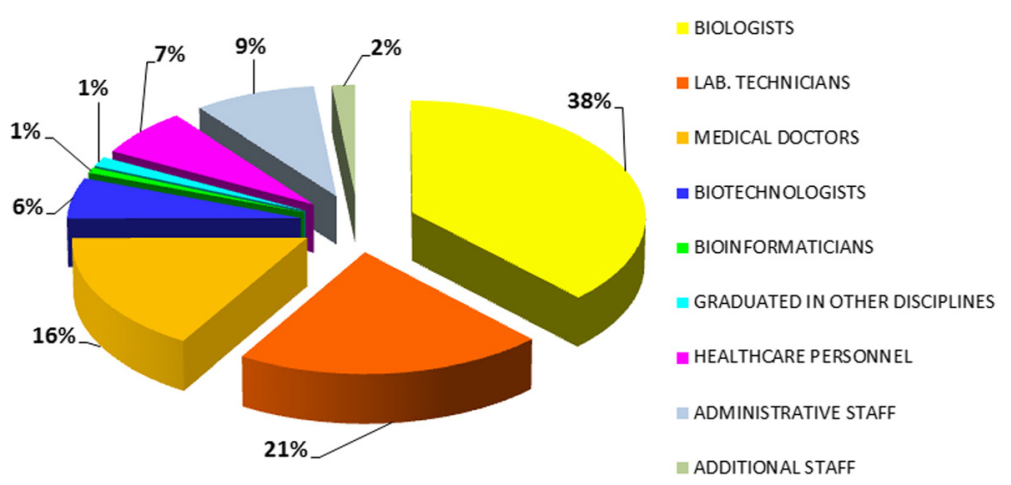

Fig. 3 Professional qualifications of the staff employed in the Italian genetic services

\section{Clinical genetic services and activity}

Forty-seven percent of 145 clinical genetic services were located in Northern regions, $23 \%$ in Central regions, and $21 \%$ in Southern/Island regions (Table 1). A total of 100,001 genetic counseling sessions were performed in 2011, mainly for single gene diseases (20\%), chromosome anomalies detected at prenatal or postnatal testing (15\%), infertility (12\%), cancer (11\%), dysmorphic syndromes (11\%), and intellectual disability disorders (7\%) (Table 6). The 2004-2011 trend of genetic counseling activity is shown in Fig. 7. The total number of registered genetic counseling sessions with respect to the laboratory diagnostic activities was quite low, only $12 \%$ (11 \% in 2007) of all genetic analyses had been accompanied by pre-test or post-test counseling.

\section{Appropriateness of the tests}

The appropriateness of genetic testing was assessed by investigating the congruence between the clinical diagnosis and the test results in nine disorders (Table 7), selected on the basis of their easily recognizable clinical phenotype and the significant number of evaluated cases. Clinical diagnosis was substantiated in $52 \%$ of patients with celiac disease, $15 \%$ with ankylosing spondylitis, $23 \%$ with Williams syndrome (3\% in 2007), $33 \%$ with DiGeorge/Velocardiofacial syndrome (3\% in 2007), $4 \%$ with fragile-X syndrome, $7 \%$ with Angelman syndrome
(9 \% in 2007), $8 \%$ with Prader-Willi syndrome (18 \% in 2007), and $45 \%$ with achondroplasia (36\% in 2007).

Worthy of note was the $4 \%$ figure of the confirmed fragile X syndrome cases. Fifteen percent of CGH-array analyses (1383 out of 9355 tests) disclosed pathogenic Copy Number Variations (CNVs), including 407 deletions resulting in known deletion syndromes.

\section{Discussion}

The survey of the Italian medical genetic centers in year 2011 was carried out on the behalf of SIGU. This study aimed at providing indications to the national and regional public health systems, in agreement with the Regional Health System request to rationalize and integrate the public genetic laboratories under the pressure of the spending review and the need to improve efficiency. Indeed, the national health system is fully supporting the cost of genetic testing requested by the specialists, with some limitations for prenatal testing in women under the age of 35 years and/or without any specific indication. Accordingly to previous reviews, the number of genetic services was exceeding that required against the approximately 60,000,000 total inhabitants. Indeed the Minister of Health and the Italian Regions suggested that the maximums should be 1,000,000 inhabitants for every clinical genetics facility between 500,000 and 1,000,000 inhabitants for every cytogenetic

Table 2 Quality assurance by accreditation or certification procedures

\begin{tabular}{|c|c|c|c|c|c|c|c|c|}
\hline $\begin{array}{l}\text { Geographical } \\
\text { area }\end{array}$ & $\begin{array}{l}\text { Accredited by } \\
\text { institutional bodies }\end{array}$ & $\begin{array}{c}\text { Also ISO } \\
9001 \text { certified }\end{array}$ & $\begin{array}{c}\text { Also ISO } \\
15189 \text { accredited }\end{array}$ & $\begin{array}{c}\text { Also ISO } \\
17025 \text { accredited }\end{array}$ & $\begin{array}{l}\text { Also } \mathrm{JCl} \\
\text { accredited }\end{array}$ & $\begin{array}{c}\text { Also EFl } \\
\text { accredited }\end{array}$ & $\begin{array}{l}\text { Also CAC } \\
\text { accredited }\end{array}$ & $\begin{array}{l}\text { Also SIGU } \\
\text { Accredited }\end{array}$ \\
\hline Northern & 109 & 83 & 13 & 0 & 7 & 4 & 1 & 9 \\
\hline Central & 42 & 31 & 7 & 1 & 1 & 2 & 0 & 3 \\
\hline Southern & 28 & 22 & 0 & 1 & 2 & 0 & 0 & 0 \\
\hline Islander & 19 & 17 & 0 & 0 & 0 & 1 & 0 & 1 \\
\hline Total $^{\mathrm{a}}$ & 198 & 153 & 20 & 2 & 10 & 7 & 1 & 13 \\
\hline$\%^{\mathrm{b}}$ & 73,8 & 57,1 & 7,4 & 0,7 & 3,7 & 2,6 & 0,3 & 4,8 \\
\hline
\end{tabular}

aTotal number of accredited/certified structures

$\mathrm{b}_{\%}$ of accredited-certified centers out of the total of the censused centers 
Table 3 Constitutional and oncological cytogenetic analyses surveyed by SIGU since 2000

\begin{tabular}{|c|c|c|c|c|c|}
\hline \multirow[b]{2}{*}{ Type of tissue/analysis } & \multicolumn{5}{|c|}{ Year } \\
\hline & 2000 & 2002 & 2004 & 2007 & 2011 \\
\hline Prenatal cytogenetic tests & & & Number & & \\
\hline Amniotic Fluid & 77395 & 95729 & 101011 & 101750 & 97320 \\
\hline Chorionic villi & 9169 & 15159 & 18357 & 25691 & 25520 \\
\hline Fetal blood & 784 & 808 & 870 & 478 & 383 \\
\hline Spontaneous abortions & 2874 & 5231 & 6483 & 8415 & 5856 \\
\hline Prenatal FISH & & 8643 & 20032 & 26331 & $2891^{a}$ \\
\hline Rapid FISH for aneuploidies & & & & & 4288 \\
\hline Microarray (CGH and SNPs) & & & & 393 & 1862 \\
\hline Total Prenatal tests & 90222 & 125570 & 146753 & 163058 & 138120 \\
\hline \multicolumn{6}{|l|}{ Postnatal cytogenetic tests } \\
\hline Peripheral blood & & 65148 & 81153 & 8,478 & 69841 \\
\hline Fibroblasts & & 493 & 1258 & 1184 & 811 \\
\hline Other & & 213 & & & 502 \\
\hline Postnatal FISH & & 4776 & 22999 & 22653 & $5819^{b}$ \\
\hline Microarray (CGH and SNPs) & & & & 1443 & 8290 \\
\hline Total Postnatal tests & 49696 & 70630 & 105410 & 108758 & 85263 \\
\hline \multicolumn{6}{|l|}{ Oncological cytogenetic tests } \\
\hline Bone marrow & & 23445 & 27323 & 34500 & 31538 \\
\hline Peripheral blood & & & & & 2873 \\
\hline Solid tumors & & 1671 & & & 2482 \\
\hline Metaphase ish & & 8383 & 4112 & 6565 & 4142 \\
\hline Interphase ish & & & & & 27821 \\
\hline Microarray (CGH and SNPs) & & & & & 1916 \\
\hline Total oncological cytogenetic tests & 15948 & 33499 & 31435 & 41065 & 70772 \\
\hline TOTAL CYTOGENETIC TESTS & 155866 & 229699 & 283598 & 312881 & 294155 \\
\hline
\end{tabular}

${ }^{\mathrm{a}} \mathrm{FISH}$ for microdeletion syndromes (897), subtelomeric regions (276), extra structurally abnormal chromosomes (599) and rearrangement (1119) characterization. ${ }^{\mathrm{b}} \mathrm{FISH}$ for microdeletion syndromes (2662), subtelomeric regions (1186), extra structurally abnormal chromosomes (455) and rearrangement (1516) characterization

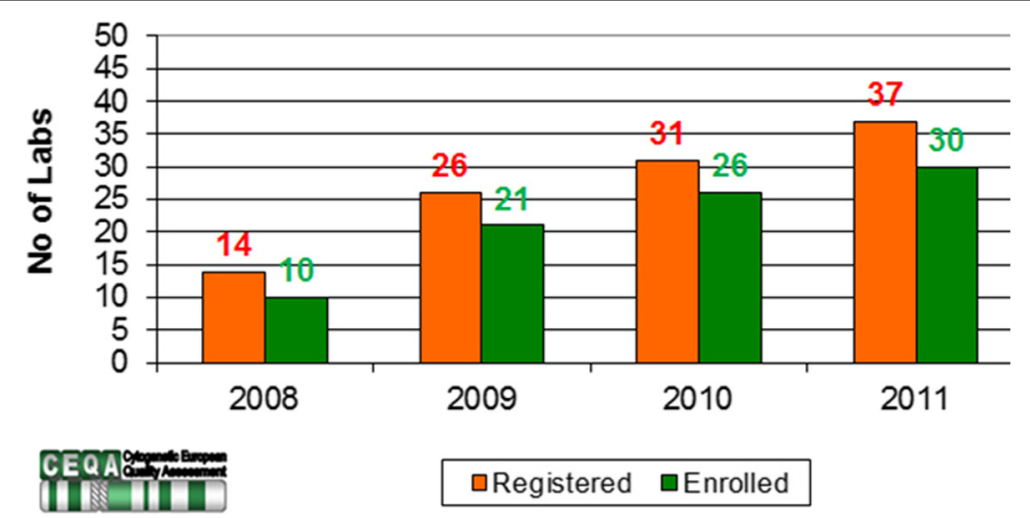

Fig. 4 CEQA Registration vs Enrolment (effective participation) of Italian Cytogenetic Laboratories during the last years 


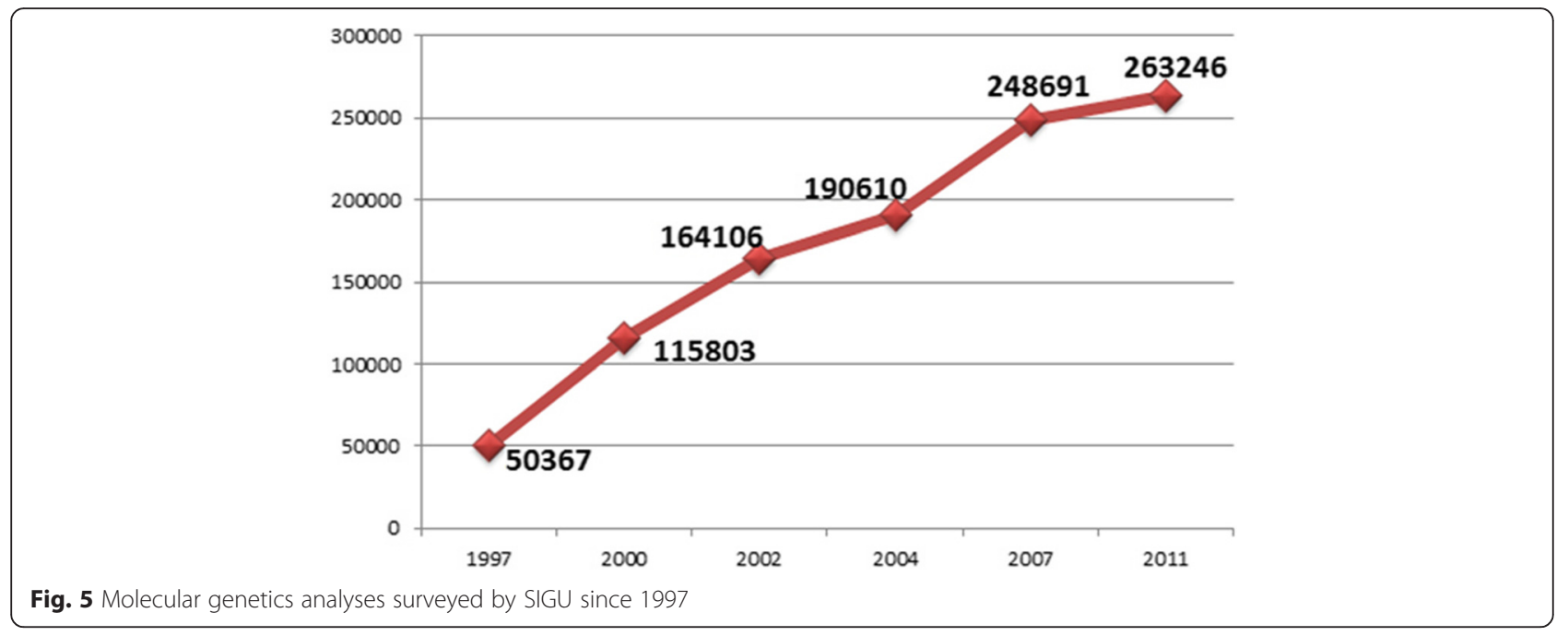

laboratory and not less than 3,000,000 inhabitants for every molecular genetic laboratory (http://www.salute. gov.it/imgs/c_17_pubblicazioni_908_allegato.pdf). The total number of genetic services in Table 1 clearly attests an oversize in all kinds of services.

As shown in this report, the coverage of the Italian territory by genetic testing facilities is one of the highest in Europe. In addition there is not equal distribution of the genetic services across the country, mainly attributable to economic reasons, since both public and private genetic services initially began in the rich regions of Northern Italy, which also are the most densely inhabited [2]. To date, only a few Italian regions have implemented strategic plans for reducing the number of centers through a coordination of their activities [4].

The SIGU 2011 survey evidenced a slightly lower number of genetic services compared to the 2007 data and confirmed that more than $50 \%$ of all genetic services were located in Northern regions. A total of 3246 health professionals worked in these services, $44 \%$ of which were biologists or biotechnologists as compared to only $21 \%$ of technicians, an Italian anomaly contrasting the trend observed in other European countries and mainly attributable to the availability of the former to accept scholarships.

In the last decade guidelines regulating the activities of clinical and laboratory genetic services were jointly

Table 4 Disease genes amenable to analysis in Italy and Europe: scenario 2007-2012

\begin{tabular}{lccc}
\hline & \multicolumn{3}{c}{ Year } \\
\cline { 2 - 4 } & 2007 & 2011 & 2012 \\
\hline $\begin{array}{l}\text { Genes tested in Europe } \\
\text { (source: Orphanet/EurogenTest) }\end{array}$ & 1500 & 1812 & 2179 \\
$\begin{array}{l}\text { Genes tested in Italy } \\
\text { (source: SIGU survey) }\end{array}$ & $556(37 \%)$ & $902(50 \%)$ & $1042(48 \%)$ \\
\hline
\end{tabular}

developed by the Ministry of Health and the Italian Regions, establishing roles and functions of genetic services [1]. According to National and Regional Health System, public Medical Genetics Services must operate within a Quality Management System, accredited by institutional bodies. Quality is defined by a number of requirements, which are not limited to organizational, professional, technical, procedural and communication elements. A significant improvement in the adoption of Quality Management Systems was registered in 2011, with respect to 2007 . Indeed, $74 \%$ of genetics structures turned out to be institutionally accredited, $57 \%$ to be also voluntarily certified according to ISO 9001 standard (28\% in 2007) and a few voluntarily accredited according to ISO 15189. About $5 \%$ of genetic services voluntarily accredited according to the quality standard for genetic structures elaborated by SIGU (www.sigu.net). The Italian state of quality systems within genetic testing services is similar to the European overview provided by Berwouts et al. [5]. Again, a North to South gradient was registered, with the majority of the accredited/certified services being located in Northern regions.

Collected data, showed that only $20 \%$ of cytogenetic laboratories participated in the accredited CEQAS (formerly CEQA) and $44 \%$ in the Istituto Superiore di Sanità (ISS, EQA national provider) schemes. Only a minority of the molecular laboratories stated they participated in an EQA scheme for cystic fibrosis. The participation in EQA is an established tool for improving quality, educating laboratory staff and directing laboratories towards best practices. National rules establish that medical laboratories shall participate in EQA scheme in order to be institutionally accredited, but appropriate checks to verify the participation of the genetic laboratories in EQA are only occasionally carried out by responsible bodies. 
Table 5 Top 15 molecular genetic tests in Italy, year 2011

\begin{tabular}{lcc}
\hline & Number & Percent \\
\hline Cystic fibrosis (CFTR) & 55716 & 21 \\
Factor V Leiden mutation (F5) & 24834 & 9 \\
Coagulation Factor II mutation (F2) & 20393 & 8 \\
MTHFR Deficit & 18526 & 7 \\
Celiac Disease (HLA) & 11824 & 4 \\
Beta thalassemia (HBB) & 7796 & 3 \\
Fragile X syndrome (FRAXA) & 7695 & 3 \\
Chronic Myeloid Leukaemia (BCR/ABL) & 7131 & 3 \\
Rheumatic Diseases (HLA) & 6431 & 2 \\
Hemochromatosis (HFE) & 5088 & 2 \\
Neurosensory deafness (GJB6) & 4895 & 2 \\
Duchenne/Becker muscular dystrophy (DMD) & 3823 & 1 \\
Breast cancer (BRCA1/2) & 3821 & 1 \\
Acute Myeloid Leukaemia & 3579 & 1 \\
Y chromosome microdeletion (AZF) & 3127 & 1 \\
Total & 184679 & 70 \\
\hline
\end{tabular}

As shown in this report, the coverage of the Italian territory by genetic testing facilities is one of the highest in Europe. Table 4 shows that the $50 \%$ of genetic tests available in Europe at time of survey were available also in Italy (902 genes investigated in 2011 compared to the 556 disease genes in 2007). Data collected by OrphanetItaly referring to year 2012 figure showed an additional increase, with 1107 investigated disease genes. This positive trend places Italy at the fourth position in Europe, after Germany, Spain, and France [3]. In the case of tests not available in Italy, disease-gene analysis is performed using cross-border facilities. According to the Kääriäinen European survey [6] including also data from Italy, about the $3 \%$ of genetic analyses in Europe are performed cross-border.

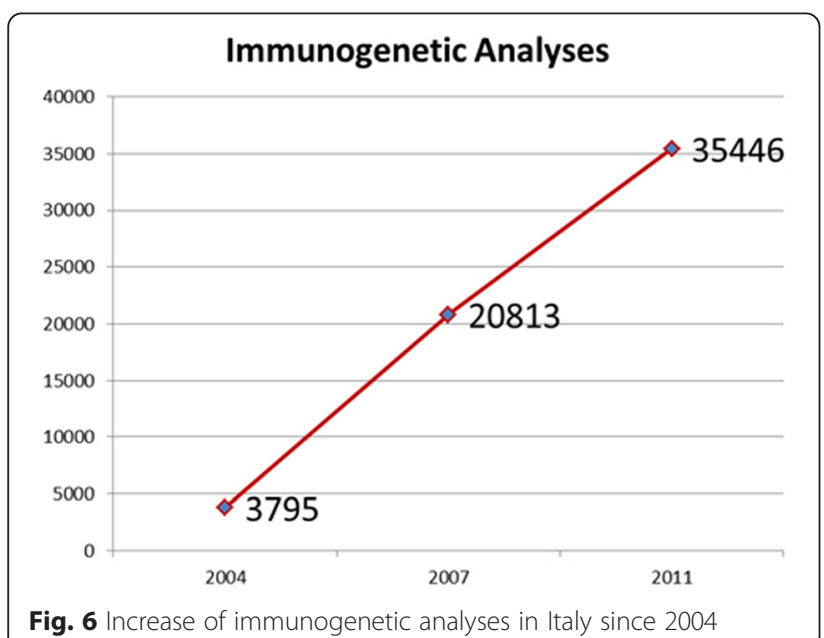

Fig. 6 Increase of immunogenetic analyses in Italy since 2004
The need for a revision of the national molecular diagnostic network and for a diversification of the offer are supported by the results of the present survey, showing that testing of 15 disease-genes only accounted for $70 \%$ of all molecular analyses in 2011. In addition, the demand of molecular tests has increased by a figure of $20 \%$ from 2007 onwards, and cytogenetic analyses has reached a plateau of around 300,000 tests per year. Compared with the results registered by the 2007 census, the request of molecularly testing the susceptibility to common disorders and complex phenotypes was not increased, the analysis of thrombophilia cascade genes and HLA accounting for about $30 \%$ of all molecular tests.

The request of constitutional prenatal and postnatal chromosome analyses has decreased in recent years. In particular, the number of genetic tests in amniocytes, which had been stable between 2004-2007, decreased in the years preceding the present survey, while the number of test on chorionic villi, increased by about 2500 per year in 2007-2011, stabilizing at around 25,500. It is expected that the decreasing trend of invasive prenatal tests will be further corroborated in the coming years, due to introduction of Non-Invasive Prenatal Testing (NIPT) into the diagnostic set.

The reduction of constitutional postnatal cytogenetic tests appears mainly related to the decrease of FISH analyses, which was expanded in the early 2000s, in parallel with the increased availability of commercial probes testing for cryptic deletions and supernumerary markers. A similar trend was also seen prenatally, with a consistent decrease of FISH tests. Between 2007-2011, FISH analyses had been progressively substituted by microarrays testing, as shown by the 8290 postnatal and 1862 prenatal tests (18 \% of the total) in 2011, compared to 1443 and 393 respectively in 2007. The reduction in FISH prenatal tests was related also to the widespread use of QF-PCR for detecting major aneuploidies.

By contrast, oncological cytogenetic tests had increased by $58 \%$, mainly as a consequence of the wider introduction of FISH interphase analysis in genetic centers as documented by Table 3 . One possible reason is the adoption of interphase FISH for detecting cryptic chromosome rearrangements in neoplastic disorders as recommended by the international guidelines.

As to previous concerns on the appropriateness of genetic testing requested by referring clinical geneticists, the 2011 results show an increase in the confirmed diagnoses for DiGeorge/Velocardiofacial and Williams syndromes, and a significant decrease for Prader-Willi syndrome compared to 2007 (see Table 7).

Only $12 \%$ of all genetic analyses were accompanied by genetic counseling, in contrast with international [7] and national recommendations $[8,9]$. Inappropriate replacement of the patient communication session by professionals 
Table 6 Reason for requesting genetic counselling in 20042011 period

\begin{tabular}{lccc}
\hline & 2004 & 2007 & 2011 \\
\hline Prenatal chromosome & 7164 & 15197 & 10316 \\
anomalies & $(13 \%)$ & $(21 \%)$ & $(10 \%)$ \\
Postnatal chromosome & 4007 & 4651 & 5394 \\
anomalies & $(7 \%)$ & $(6 \%)$ & $(5 \%)$ \\
Dysmorphic disorders & 9967 & 9800 & 11129 \\
& $(18 \%)$ & $(14 \%)$ & $(11 \%)$ \\
Mendelian disorders & 8072 & 10765 & 20461 \\
& $(15 \%)$ & $(15 \%)$ & $(20 \%)$ \\
Intellectual disability & 5501 & 5756 & 7294 \\
& $(10 \%)$ & $(8 \%)$ & $(7 \%)$ \\
Cancer & 2548 & 3435 & 11303 \\
& $(5 \%)$ & $(5 \%)$ & $(11 \%)$ \\
Infertility & 2984 & 6128 & 12012 \\
& $(5 \%)$ & $(8 \%)$ & $(12 \%)$ \\
Recurrent abortion & 1919 & 2930 & 6109 \\
& $(4 \%)$ & $(4 \%)$ & $(6 \%)$ \\
Exposure to & 2437 & 2944 & 1622 \\
teratogenic agents & $(4 \%)$ & $(4 \%)$ & $(2 \%)$ \\
Other & 8001 & 8548 & 12350 \\
& $(15 \%)$ & $(12 \%)$ & $(12 \%)$ \\
Total & 54604 & 72161 & 100001 \\
\hline
\end{tabular}

$\%, \%$ of reason for demanding genetic counselling out of the total of the requests

of contiguous fields could account for the poor detection rate in these syndromes.

Since 2011 no substantial changes have been introduced in the Italian public genetic diagnostic field. In fact, the more recently developed tests (NGS: Next
Generation Sequencing; NIPT) have not yet entered in the diagnostics setting and remain restricted to a research application. Public healthcare in Italy is now administrated on a regional basis and a concerted effort must be made to review and rationalize the network of genetic services nationally, taking into account the results of this present survey. In fact, this study provides a real and detailed representation about the logistic of the genetic centers, the number of performed genetic tests, the quality of provided services, the appropriateness of genetic test requests and the number of employees. Within this setting, a number of recommendations can be given for improving genetic services in Italy, which is at present oversized and nonharmonious. Some priority issues are emerging, including management of quality systems in terms of accreditation, certification, and EQA participations; accessibility of pre-test and post-test genetic counseling; the need of increasing availability of genetic testing for rare diseases; the development of national plans and strategies for implementing next generation technologies and advising on the clinical utility of genetic testing for complex disorders. The quality standard for genetic structures elaborated by SIGU may be adopted by a national competent body responsible for the specific accreditation and quality assurance of the genetic services. Another challenge, focused by Battista et al. [4], refers to the need of reconfiguring the professional roles and responsibilities. An additional effort concerns the education and training of those prescribing genetic tests, which should be utilized as a valuable support to good clinical practice and evidence based

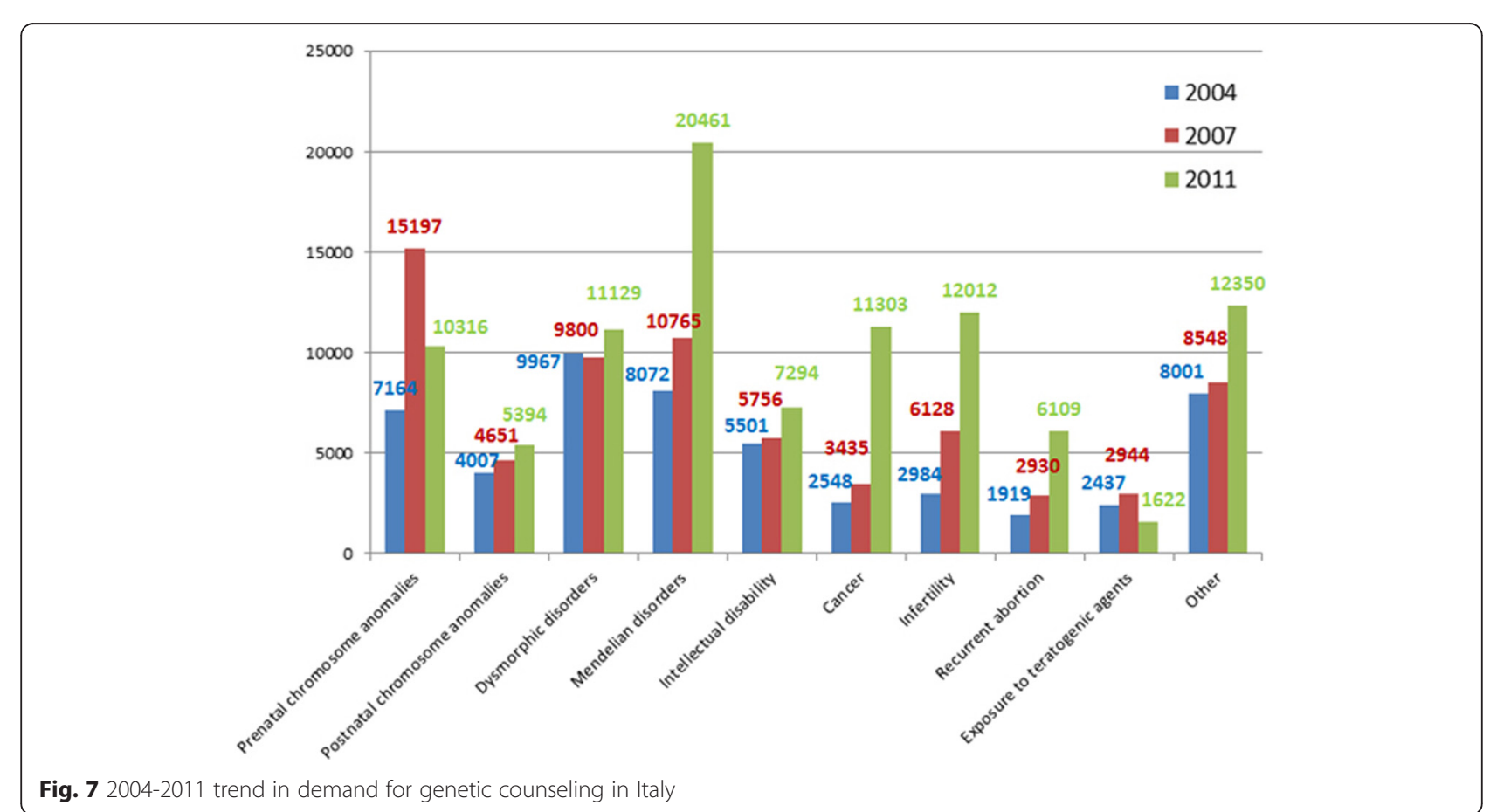


Table 7 Appropriateness of the requests for genetic testing in seven rare disorders and 2007-2011 trend

\begin{tabular}{|c|c|c|c|c|c|}
\hline Disorder & $\begin{array}{c}\text { No. of clinically } \\
\text { evaluated individuals }\end{array}$ & $\begin{array}{l}\text { No. of cases confirmed } \\
\text { by genetic testing }\end{array}$ & $\%$ of positive test (2011) & $\%$ of positive test (2007) & $\begin{array}{l}\text { Trend from } \\
\text { last survey }\end{array}$ \\
\hline Williams Syndrome & 610 & 149 & 24 & 3 & ++ \\
\hline DiGeorge/Nelocardiofacial Syndrome & 2260 & 736 & 33 & 3 & ++ \\
\hline Fragile $X$ Syndrome & 8240 & 353 & 4 & 4 & $=$ \\
\hline Achondroplasia & 186 & 84 & 45 & 36 & + \\
\hline Noonan Syndrome & 968 & 267 & 28 & $\mathrm{NE}$ & \\
\hline Angelman Syndrome & 713 & 49 & 7 & 9 & - \\
\hline Prader-Willi Syndrome & 927 & 78 & 8 & 18 & -- \\
\hline Ankylosing spondylitis & 2826 & 418 & 15 & $\mathrm{NE}$ & \\
\hline Celiac diseases & 6748 & 3488 & 52 & $\mathrm{NE}$ & \\
\hline
\end{tabular}

NE not evaluated

++ significant improvement

+ improvement

= no variations

- worsening

- significant worsening

medicine. A parallel commitment must be to inform citizens, nowadays exposed to an ever more present and available direct-to-consumergenetic testing which has little proven clinical utility.

\section{Conclusions}

This study provides a real and detailed representation about the logistics of the genetic centers operating in Italy, the quality of their provided services, the number of performed genetic tests, and the number of employees. There are too many genetic services given the population size of Italy and they are not equally distributed across the country. Quality assurance of the genetic services may be improved through a specific accreditation standard. Good clinical practice and evidence based medicine may be implemented through the education and training of the people involved in the prescriptions of genetic tests. The finding that $70 \%$ of all molecular analyses performed in 2011 was related to only 15 disease-genes, strongly supports the need for a revision of the national molecular diagnostic network. All together, these results provide information useful for improving genetic services in Italy.

\footnotetext{
Abbreviations

ASLs: Aziende Sanitarie Locali; CEQA: Cytogenetics European Quality Assessment; CEQAS: Cytogenetics European Quality Assessment Service; $\mathrm{CGH}$ : comparative genomic hybridization; CNVs: copy number variations; EFI: European Federation for Immunogenetics; EQA: external quality assessment; FISH: fluorescent in situ hybridization; IRCCS: Istituti di Ricovero e Cura a Carattere Scientifico; ISH: in situ hybridization; ISO: International Organization for Standardization; ISS: Istituto Superiore di Sanità; JCl: Joint Commission International; NGS: next generation sequencing; NIPT: noninvasive prenatal testing; QF-PCR: quantitative fluorescent. Polymerase Chain Reaction; SIGU: Italian Society of Human Genetics; SNPs: single nucleotide polymorphisms.
}

\section{Competing interests}

The authors declare that they have no competing interests.
Authors' contributions

DG wrote the manuscript and contributed to the analysis and interpretation of the data. RM and TL collected, analyzed and contributed to the interpretation of the data. AA and LL provided critical revisions for important intellectual content. BD conceived, designed, coordinated the study and contributed to the interpretation of the data. All authors have read and approved the final manuscript.

\section{Acknowledgments}

The authors are grateful to all Medical Genetic Services that participated in this survey.

The authors also warmly thank Rosalind Hastings, Scheme Director of the CEQAS (Cytogenetic European Quality Assessment Service), based at John Radcliffe Hospital, Oxford University Hospitals NHS Trust (Oxford, UK) and Domenica Taruscio, Scheme Director of the Genetic Tests Italian External Quality Assessment (EQA) coordinated by the Italian National Centre for rare Diseases -Istituto Superiore di Sanità (Rome, Italy), for providing information regarding the EQA participation of the Italian laboratories.

\section{Author details}

${ }^{1}$ Laboratorio di Citogenetica, IRCCS Istituto Auxologico Italiano, Milano, Italy. ${ }^{2}$ RRCCS Ospedale Pediatrico Bambino Gesu, Roma, Italy. ${ }^{3}$ Dipartimento di Scienze Mediche, Azienda Ospedaliera Città della Salute e della Scienza, Università di Torino, Torino, Italy. ${ }^{4}$ Genetica Medica, Dipartimento di Scienze della Salute, Università degli Studi di Milano, Milano, Italy.

Received: 18 August 2014 Accepted: 7 March 2016

Published online: 17 March 2016

\section{References}

1. Dallapiccola B, Torrente I, Morena A, Dagna-Bricarelli F, Mingarelli R. Genetic testing in Italy, year 2004. Eur J Hum Genet. 2006;14:911-16.

2. Dallapiccola B, Torrente I, Agolini E, Morena A, Mingarelli R. A Nationwide Genetic Testing Survey in Italy, Year 2007. Genet Test Mol Biomarkers. 2011;14:17-22.

3. EUCERD 2013 report on the state of the art of rare disease activities in Europe. http://www.eucerd.eu/upload/file/Reports/2013ReportStateofArtRDActivities.pdf

4. Battista RN, Blancquaert I, Laberge A-M, van Schendel N, Leduc N. Genetics in Health Care: An Overview of Current and Emerging Models. Public Health Genomics. 2012;15:34-45.

5. Berwouts S, Fanning K, Morris MA, Barton DE, Dequeker E. Quality assurance practices in Europe: a survey of molecular genetic testing laboratories. EJHG. 2012;20:1118-26.

6. Cross Border Genetic Testing for Rare Diseases. EUCERD Joint Action WP8: http://ec.europa.eu/chafea/documents/health/prague-rd-kaarianen_en.pdf 
7. OECD (2007) Guidelines for quality assurance in molecular genetic testing. http://www.oecd.org/science/biotech/38839788.pdf

8. SIGU quality standards. http://www.sigu.net/

9. Autorizzazione n. 8/2013 - Autorizzazione generale al trattamento dei dati genetici. Available at http://www.garanteprivacy.it/web/guest/home/ docweb/-/docweb-display/docweb/2818993.

Submit your next manuscript to BioMed Central and we will help you at every step:

- We accept pre-submission inquiries

- Our selector tool helps you to find the most relevant journal

- We provide round the clock customer support

- Convenient online submission

- Thorough peer review

- Inclusion in PubMed and all major indexing services

- Maximum visibility for your research

Submit your manuscript at www.biomedcentral.com/submit 